Original Article

\title{
Correlation between rounded shoulder posture, neck disability indices, and degree of forward head posture
}

\author{
Eun-Kyung Kim, PT, PhD ${ }^{1)}$, Jin SeOP KIm, PT, $\mathrm{PhD}^{2)^{*}}$ \\ 1) Department of Physical Therapy, Seonam University, Republic of Korea \\ 2) Department of Physical Therapy, Sunmoon University: 70 Sunmoonro, 221 Beongil, \\ Tangjeong-Myeon, Asansi, Chungnam 336-708, Republic of Korea
}

\begin{abstract}
Purpose] The present study aimed to examine the correlation between rounded shoulder posture, neck disability indices and the degree of forward head posture. [Subjects and Methods] Subjects aged 19-24 years were selected for this study, and the craniovertebral angle was used to measure the degree of forward head posture in the standing and seated positions. Vernier calipers were used to measure rounded shoulder posture in the supine position, and neck pain and functional disability were assessed using neck disability indices. [Results] Angle and neck disability indices in both standing and sitting posture positions exhibited a significant inverse relationship. However, no significant correlation was detected between the craniovertebral angle and rounded shoulder posture for the standing and sitting posture positions. [Conclusion] In conclusion, it was demonstrated in the present study that, depending on the degree of forward head posture, changes were detected in the neck disability indices. However, even an increase in the forward head tilt angle did not lead to rounded shoulder posture. Therefore, maintaining proper posture may prevent postural pain syndrome, functional disability, and postural deformity. Key words: Forward head posture, Rounded shoulder posture, Neck disability index
\end{abstract}

(This article was submitted May 9, 2016, and was accepted Jul. 7, 2016)

\section{INTRODUCTION}

Poor posture is common during adolescence, and the popularization of personal computers has led to sustained and frequent periods of sitting behind monitors, and visual display terminal syndrome ${ }^{1)}$. Long-term use of smart phones exposes individuals to cumulative trauma disorder caused by maintaining the same posture for long periods of time ${ }^{2)}$. The weight of the head takes up $1 / 7$ of the body weight; therefore, maintaining a still position with the head leaning forward exerts 3.6 times more force than is required to maintain the same position with straight standing posture ${ }^{3)}$.

Forward head posture (FHP) is the structural forward positioning of the head away from the centerline of the body, where lower cervical vertebrae are bent and upper cervical vertebrae are extended, and the weight of the head supported by the neck is increased ${ }^{2,4)}$. The bending moment of the head applies pressure on muscles and joints around the cervical vertebra ${ }^{5)}$, in addition to active myofascial trigger points of the suboccipital muscle which may induce tension type headaches ${ }^{6}$, , neck pain $^{7)}$ and cervical headaches, while reducing the mobility of the neck ${ }^{8)}$.

As a compensatory action for the postural deformity of FHP, severe extension arises between the upper cervical joint and atlanto-occipital joint, and the upper cervical vertebrae relatively protrude forward while the face directs upwards ${ }^{5}$. Change in the curvature of the neck bone causes upper-crossed syndrome due to an imbalance in muscular pattern ${ }^{9}$, which subsequently leads to rounded shoulder posture $(\mathrm{RSP})^{10)}$. Rounded shoulder is a protrusion of the acromion of the shoulder joint relative to the centerline of gravity of the body, causing stooped posture along with elevation, protraction, and downward

\footnotetext{
*Corresponding author. Jin Seop Kim (E-mail: skylove3373@sunmoon.ac.kr)

(C)2016 The Society of Physical Therapy Science. Published by IPEC Inc.

This is an open-access article distributed under the terms of the Creative Commons Attribution Non-Commercial No Derivatives (by-nc-nd) License $<$ http://creativecommons.org/licenses/by-nc-nd/4.0/>.
} 
rotation of the scapula, and an increased angle between the lower neck bone and upper spine ${ }^{9-11)}$.

Janda described the simultaneous occurrence of FHP and rounded shoulder as upper-crossed syndrome ${ }^{9)}$. Fernández-delas-Peñas and others have demonstrated that FHP induces tension headaches ${ }^{6)}$.

Therefore, FHP that causes round shoulder and neck pain due to an imbalance between the curvature of the spine and muscles that are attached to the neck bone, is correlated with problems in the neck bone. While several interventional studies are underway to improve FHP, research on the correlation between round shoulder and neck pain remains incomplete. Hence, the present study aimed to specifically examine the correlation between RSP, neck pain and degree of FHP using objective data.

\section{SUBJECTS AND METHODS}

A total of 126 college students (95 males, 31 females) aged 19-24 who were currently enrolled in a health program at a university situated in Namwon city, Jeollabuk-do were sampled and studied from March, 2015 to April, 2016. Before the experiment, according to the Declaration of Helsinki, the purpose and procedures of the study were fully explained to all subjects, and all subjects subsequently voluntarily agreed to enroll in the present study. General characteristics of the subjects were measured, including age $(23.9 \pm 1.5$ years $)$, height $(172.3 \pm 6.4 \mathrm{~cm})$, and weight $(69.1 \pm 13.9 \mathrm{~kg})$. Subjects who had no inherent spinal deformity, had not received spinal surgery, regularly received drugs or treatment for pain relief, and had neurological problems were excluded from the study.

To measure the craniovertebral angle (CVA) of FHP, thread with a pendulum was fixed on the ceiling, with plumb line used as the standard. A landmark was attached to the 7th neck bone and tragus of each subject, and a digital camera (Canon, EOS 7D Mark II, Japan) was installed $1.5 \mathrm{~m}$ away from the side of the subjects, while maintaining a horizontal level with the landmark ${ }^{12)}$. When capturing images in a standing position, subjects were directed to maintain natural head posture through self-balance posture, in which the subjects were instructed to bend and extend their head a maximum of three times, and to relax both arms and place by their sides. To prevent posture change due to vision, the subjects were instructed to fix their sight on the mirror stationed in front of them and were photographed three times ${ }^{12,13)}$. When capturing images in a sitting position, subjects placed their arms by the sides of their body, relaxed, and were photographed in the same manner as for the standing position. For angle measurement, ImageJ (version1.46j, National Institutes of Health, USA) software was used. The angle created by the horizontal line drawn perpendicular to the plumb line that intersects the landmark on the 7th neck bone and the line that connects the 7 th neck bone and tragus was defined as $\mathrm{CVA}^{5,6)}$. A lower CVA signifies an increase in the bend of lower cervical vertebrae ${ }^{13}$.

RSP measurement was performed using the supine method. Male subjects were instructed to take off their top and female students were asked to expose their dominant shoulder girdle. Subjects were then directed to place both arms in a neutral position while maintaining a comfortable and relaxing supine position. For RSP assessment, vernier calipers were used to measure the distance between the acromion of the shoulder joint and the table surface three times, and the numbers were averaged and used for analysis. Increased distance signifies higher RSP severity ${ }^{10)}$.

Neck disability indices (NDI) were used to measure neck pain and functional disability, and consisted of 10 items: degree of pain, daily living, lifting, reading, headache, concentration level, work, driving, sleep and leisure activity, each of which was graded from 0 to 5, to a total of 0-50. 0-4 represented no disability, 5-14, mild disability, 15-24, moderate disability, 25-34, severe disability, and $\geq 35$, complete disability ${ }^{14)}$.

Measured data were analyzed using PASW Statistics ver. 18.0, and their mean values and standard deviation were calculated. Pearson's correlation analysis was used to analyze correlations among CVA in the standing position, CVA in the sitting position, RSP, and NDI. All statistical significance levels were $\alpha=0.05$.

\section{RESULTS}

CVA of subjects in the standing position was $6.4 \pm 5.7$, as compared with $59.7 \pm 6.9$ in the sitting position. RSP was $9.2 \pm 1.5$, and NDI were $4.9 \pm 3.9$ (Table 1). Correlation coefficient analysis between CVA and NDI in standing position demonstrated $\mathrm{r}=-0.35$, indicating a significant negative correlation; whereas $\mathrm{r}=-0.33$ was determined for the sitting position, indicating a similarly significant negative correlation. However, no significant correlation was detected between CVA and RSP in the standing and sitting positions (Table 2).

\section{DISCUSSION}

Each part of the body signifies a location within the epidemiological order and environment ${ }^{15)}$. Poor posture is common during adolescence ${ }^{1)}$. Moreover, long-term use of smartphones and personal computers causes FHP, stiffness in the muscles around the neck, chest and back, leads to an imbalance in muscular pattern, reduces the epidemiological function of the body, and weakens soft tissues. Previous studies have demonstrated that the pectoralis, upper trapezius, and levator scapulae muscles are shortened, and upper-crossed syndrome is caused by weakened deep cervical flexors, lower trapezius, rhomboid, and serratus anterior muscles. FHP causes RSP and limits the working range of the head and neck due to pain ${ }^{9,10,16) .}$ 
Table 1. Mean and standard deviation of measured values of CVA on standing position, CVA on sitting position, RSP, and NDI

\begin{tabular}{lccc}
\hline CVA on standing position CVA on sitting position & RSP & NDI \\
\hline $61.4 \pm 5.7 *$ & $59.7 \pm 6.9$ & $9.2 \pm 1.5$ & $4.9 \pm 3.9$ \\
\hline *Mean \pm SD. \\
CVA: craniovertebral angle; RSP: rounded shoulder posture; NDI: neck disability indexes
\end{tabular}

Table 2. Correlation of CVA on standing position, CVA on sitting position, RSP, and NDI

\begin{tabular}{lcccc}
\hline & $\begin{array}{c}\text { CVA } \\
\text { on standing position }\end{array}$ & $\begin{array}{c}\text { CVA } \\
\text { on sitting position }\end{array}$ & RSP & NDI \\
\hline $\begin{array}{l}\text { CVA } \\
\text { on standing position }\end{array}$ & 1 & & & \\
CVA & & & & \\
on sitting position & $0.802^{*}$ & 1 & 1 & \\
RSP & -0.037 & 0.084 & 0.104 & 1 \\
NDI & $-0.359^{*}$ & $-0.336^{*}$ & \\
\hline
\end{tabular}

$* \mathrm{p}<0.01$

A total of 126 students were enrolled as subjects for the present study, and their CVA was measured in both standing and sitting positions to measure the degree of FHP. Furthermore, as CVA was hypothesized to have an effect on RSP and the degree of neck pain, these correlations were also investigated.

The results indicated that CVA was $61.4 \pm 5.7$ in the standing position, as compared with $59.7 \pm 6.9$ in the sitting position. RSP was $9.2 \pm 1.5$, exhibiting no significant correlation with CVA. It is evident that the FHP angle measured in the present study is not within the range that could cause the deformity of RSP. Nemmers and others set the limit of FHP as $<53^{\circ}$ of CVA $^{13,17,18)}$. However, while Yip and others ${ }^{8)}$ suggested that lower CVA led to a higher frequency of neck pain, they did not propose a certain angle range to identify FHP. Therefore, the study exhibited a limitation in finding the specific decrement in CVA that causes RSP.

Gore and others ${ }^{19}$ ) identified FHP as a cervical lordosis angle (CLA) of $<21^{\circ}$ and a neck bone joint working range of $<70^{\circ 20}$. Future research is recommended to compare CVA and CLA and elucidate a RSP range that corresponds to the degree of FHP.

In the present study, to assess the degree of rounded shoulder, the height of the acromion of the dominant shoulder joint was measured in the supine position. While this method is reliable for determining signs of RSP, it is typically used to measure the length of the pectoralis minor muscle ${ }^{21)}$. The height of the acromion of the dominant shoulder joint of only one side was measured to gauge RSP and, as it was measured in supine position ${ }^{10)}$, there was a limitation in determining deformity of spinal bending and positional change of the scapula due to FHP. Measurement of RSP may vary depending on the position of the anatomical point of the acromion, as could the position of the neck bone $\mathrm{C} 7$ ( 7 th cervical spinous process) depending on posture. Therefore, it cannot be concluded that a decrease in CVA certainly leads to an increase in RSP. Equipment with high reliability must be used for accurate measurement of posture in order to minimize the margin of error. Nevertheless, a previous study by Wong and others demonstrated a significant decrease in RSP in 28 healthy subjects with RSP after soft tissue mobilization was administered to the shortened pectoralis minor muscle ${ }^{22}$.

As a negative correlation was observed between CVA in both standing and sitting positions and neck pain, a decrease in CVA due to FHP could be demonstrated to cause neck pain. CVA in the standing position was $61.4 \pm 5.7,59.7 \pm 6.9$ in sitting position, and NDI were $4.9 \pm 3.9$, which is in the mild disability range. That is, it suggests the angle of FHP at which neck pain and disability begin to appear.

FHP at which the head bending moment increases applies pressure to extensors, such as the semispinalis capitis and levator scapulae muscles, by itself regardless of any inducer. Moreover, maintaining the extended position constantly to adjust the eye level causes fatigue in the muscles at the back of the neck ${ }^{5)}$. In addition, a decrease in CVA by FHP leads to physiological limitations due to the excessive pressure on the facet joint, thus suggesting the possibility of pain. Silva and others reported that FHP causes physiological limitations, such as excessive pressure on the facet joint, elongation of neck muscles and shortening of tail muscles, which induce pain due to excessive tension in the capsular ligament ${ }^{7}$. An increase in the active myofascial trigger points of suboccipital muscle by FHP may lead to chronic tensional headaches, and Martin-Herrero and others have demonstrated a proportional correlation between NDI and the Pittsburg sleep quality index ${ }^{23)}$.

In conclusion, the results of the present study demonstrated that a correlation was detected between FHP and neck pain and disability. However, no correlation was observed between the angle of FHP (measured by CVA) and RSP. Future research is required to examine the association between RSP and the degree of FHP using more accurate measurement methods. 
Furthermore, proper postural habits and posture training exercises are recommended to prevent postural deformity, postural pain syndrome, and functional disability.

\section{REFERENCES}

1) Cho CY: Survey of faulty postures and associated factors among Chinese adolescents. J Manipulative Physiol Ther, 2008, 31: 224-229. [Medline] [CrossRef]

2) Szeto GP, Straker L, Raine S: A field comparison of neck and shoulder postures in symptomatic and asymptomatic office workers. Appl Ergon, 2002 , 33: 75-84. [Medline] [CrossRef]

3) Park SY, Yoo WG: Effects of the sustained computer work on upper cervical flexion motion. J Phys Ther Sci, 2014, 26: 441-442. [Medline] [CrossRef]

4) Harrison DE, Harrison DD, Betz JJ, et al.: Increasing the cervical lordosis with chiropractic biophysics seated combined extension-compression and transverse load cervical traction with cervical manipulation: nonrandomized clinical control trial. J Manipulative Physiol Ther, 2003, 26: 139-151. [Medline] [CrossRef]

5) Cailliet R: Softtissue pain and disability. 2nd ed. Philadelphia: F.A. Davis co, 1998.

6) Fernández-de-las-Peñas C, Alonso-Blanco C, Cuadrado ML, et al.: Forward head posture and neck mobility in chronic tension-type headache: a blinded, controlled study. Cephalalgia, 2006, 26: 314-319. [Medline] [CrossRef]

7) Silva AG, Punt TD, Sharples P, et al.: Head posture and neck pain of chronic nontraumatic origin: a comparison between patients and pain-free persons. Arch Phys Med Rehabil, 2009, 90: 669-674. [Medline] [CrossRef]

8) Yip CH, Chiu TT, Poon AT: The relationship between head posture and severity and disability of patients with neck pain. Man Ther, 2008, 13: 148-154. [Medline] [CrossRef]

9) Janda V: Muscles and motor control in cervicogenic disorders. New York: Churchill Livingstone, 1994

10) Sahrmann SA: Diagnosis and treatment of movement impairment syndromes. St. Louis: Mosby, 2002.

11) Lukasiewicz AC, McClure P, Michener L, et al.: Comparison of 3-dimensional scapular position and orientation between subjects with and without shoulder impingement. J Orthop Sports Phys Ther, 1999, 29: 574-583, discussion 584-586. [Medline] [CrossRef]

12) Harman K, Hubley-Kozey CL, Butler H: Effectiveness of an exercise program to improve forward head posture in normal adults: a randomized, controlled 10-week trial. J Manual Manip Ther, 2005, 13: 163-176. [CrossRef]

13) Raine S, Twomey LT: Head and shoulder posture variations in 160 asymptomatic women and men. Arch Phys Med Rehabil, 1997, 78: 1215-1223. [Medline] [CrossRef]

14) Vernon H, Mior S: The Neck Disability Index: a study of reliability and validity. J Manipulative Physiol Ther, 1991, 14: 409-415. [Medline]

15) Shumway-Cook A, Woollacott M: Motor Control: Translating researchinto clinical practice, 3rd ed. Philadelphia: Lippincott Williams \& Wilkins, 2007.

16) Kendall FP, McCreary EK, Provance PG, et al.: Muscle testing and function with posture and pain, 5th ed. Baltimore: Lippincott Williams \& Wilkins, 2005.

17) Nemmers TM, Miller JW, Hartman MD: Variability of the forward head posture in healthy community-dwelling older women. J Geriatr Phys Ther, 2009, 32 : 10-14. [Medline] [CrossRef]

18) Kim SY, Kim NS, Kim LJ: Effects of cervical sustained natural apophyseal glide on forward head posture and respiratory function. J Phys Ther Sci, 2015, 27: 1851-1854. [Medline] [CrossRef]

19) Gore DR, Sepic SB, Gardner GM: Roentgenographic findings of the cervical spine in asymptomatic people. Spine, 1986, 11: 521-524. [Medline] [CrossRef]

20) Neumann DA: Kinesiology of the musculoskeletal system: Foundations for rehabilitation, 2nd ed. Missouri: Mosby, 2010.

21) Lewis JS, Valentine RE: The pectoralis minor length test: a study of the intra-rater reliability and diagnostic accuracy in subjects with and without shoulder symptoms. BMC Musculoskelet Disord, 2007, 8: 64-73. [Medline] [CrossRef]

22) Wong CK, Coleman D, diPersia V, et al.: The effects of manual treatment on rounded-shoulder posture, and associated muscle strength. J Bodyw Mov Ther, 2010, 14: 326-333. [Medline] [CrossRef]

23) Martín-Herrero C, Rodrigues de Souza DP, Alburquerque-Sendín F, et al.: [Myofascial trigger points, pain, disability and quality of sleep in patients with chronic tension-type headache: a pilot study]. Rev Neurol, 2012, 55: 193-199. [Medline] 